\title{
INTELLIGENT WINDCATCHER - A COMBINATION OF MODERN AND TRADITIONAL TECHNOLOGY
}

\author{
Masoud Poshtiban \\ Department of Art and Architecture \\ Azad University of Tabriz, Tabriz, Iran \\ masoud_poshtiban@yahoo.com
}

\author{
Reza Banaei Khosroushahi \\ Department of Electrical Engineering \\ Sahand University of Technology, Tabriz, Iran \\ rbanaei@sut.ac.ir, rbanaei@gmail.com
}

\author{
Somayyeh Poshtiban \\ Microelectronic research Center \\ Urmia University, Urmia, Iran \\ nposhtiban@yahoo.com
}

\begin{abstract}
In this paper, a novel idea to prepare indoor fresh air by an environmentally friendly way is proposed. In this design we are inspired by traditional windcatchers which have been being used for centuries in torrid region of Iran. Theirs unique feature of in-dependency to costly energy sources have made them suitable choices specially for not fully developed areas. We devised an intelligent windcatcher which can adapts itself according to outside weather conditions to maximize the performance of indoor air conditioning. Design procedure in addition to simulation results are presented and the advantages of the proposed design are discussed.
\end{abstract}

\section{KEYWORDS}

Windcatcher, Badgir, Fuzzy Controller

\section{INTRODUCTION}

A windcatcher, or Badgir (in Persian), is a traditional Persian architectural device have been used for several centuries to create natural ventilation in buildings. It is not known who first invented the windcatcher, but it still can be seen in many countries today. Windcatchers come in various designs, such as the unidirectional, bidirectional, and multi-directional.

The windcatcher functions on several principles: First, a windcatcher is capped and has several directional ports at the top (Traditionally four). By closing all but the one facing away from the incoming wind, air is drawn upwards using the coanda effect, similar to how opening the one facing the wind would push air down the shaft. This generates significant cooling ventilation within the structure below, but is not enough to bring the temperature below ambient alone - it would simply draw hot air in through any cracks or windows in the structure below. Therefore, he key to generating frigid temperatures seems to be that there are very few cracks at the base of the thick structure below, but there is a significant air gap above the qanat. A qanat has quite a lot of water inside, because there are frequent well-like reservoirs along its path. Completely shaded from the sun, a qanat also aggregates the cold, sinking air of the night, which is then trapped within, unable to rise up to the less dense surface air. A windcatcher, however, can create a pressure gradient which sucks at least a small amount of air upwards through a house. This cool, dry night air, being pulled over a long passage of water, evaporates some of it and is cooled down further. Finally, in a windless environment or waterless house, a windcatcher functions as a stack effect aggregator of hot air. It creates a pressure gradient which allows less dense hot air to travel upwards and escape out the top. This is also compounded 
significantly by the day-night cycle mentioned above, trapping cool air below. The temperature in such an environment can't drop below the nightly low temperature. These last two functions have gained some ground in Western architecture, and there are several commercial products using the name windcatcher. When coupled with thick adobe that exhibits high heat transmission resistance qualities (R-value), the windcatcher is able to chill lower level spaces in mosques and houses in the middle of the day to frigid temperatures [1].

So effective has been the windcatcher in Persian architecture that it has been routinely used as a refrigerating device (yakhchal) for ages. Many traditional water reservoirs are built with windcatchers that are capable of storing water at near freezing temperatures for months in summer. High humidity environments destroy the evaporative cooling effect enjoyed in the dry conditions seen on the Iranian plateau; hence the ubiquitous use of these devices in drier areas such as Yazd, Kashan, Nain, and Bam. A badgir is depicted in Fig. 1.

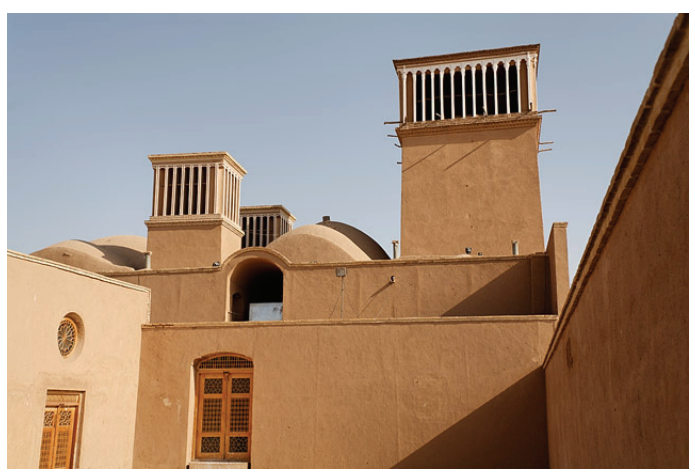

Figure 1 Badgirs in Persian Cities

\section{PROPOSED DESIGN}

In this paper, a novel idea for embedding a cheap cooling system in buildings is proposed. In this design, air conditioning energy is totally provided by wind power. Moreover the remained small amount of the energy needed by intelligent system and actuator are gathered from sunlight via mounted solar cells. Also a sealed lead-acid battery (like those used in cars) is charged by solar cells and provide the auxiliary power source for nights or cloudy days. So there is no need to other costly energy sources.

The proposal is based on traditional windcatchers which are even now in use in some of Iran cities which are near deserts. In this design, the intelligent windcatcher has the ability to rotate freely in 360 degree by means of a rotating shaft. In order to reduce the necessary torque to move the shaft, a gearbox is devised. The gears around the windcatcher make the gear with large radius and the gear with small radius is coupled to motorgearbox actuator. So the rotation of the windcatcher can be performed even with a small DC motor in this way. The mentioned DC motor is energized by a PWM driver circuit which amplifies the control action signals and get it to motor with high efficiency and little thermal waste. The base controller is a classic PI (ProportionalIntegral) controller that forms a feedback control scheme by using the error signal made by subtracting the windcatcher direction sensor's signal $\theta_{L}$ from reference direction signal $\theta_{r}$.

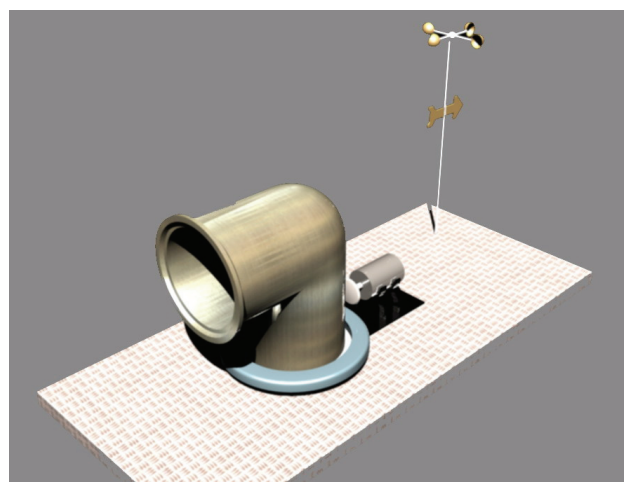

Figure 2 3D View of the System

The reference direction signal is obtained from the Fuzzy supervisory controller. The fuzzy controller decides intelligently in which direction and to what position should the windcatcher rotate. The Fuzzy Controller make its decisions by analyzing the sensors information. We employed several sensors to get the information about wind direction, wind speed, ambient temperature and battery voltage. All of these information help the Fuzzy controller to make correct and optimal decisions... 


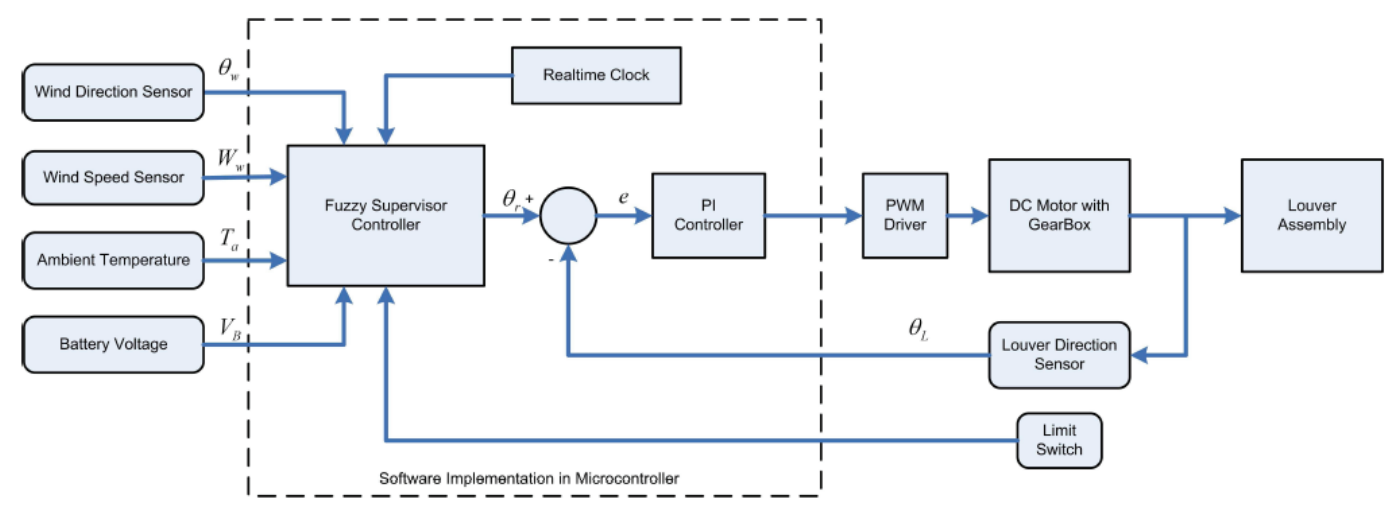

Figure 3. Complete System Diagram

Required electrical energy is completely provided using small-in-size solar cells. However to ensure that the system is always online, an other backup system is mounted which is actually a 12 volt sealed Lead-Acid battery. The implementation of the proposed controllers can be done using a microcontroller circuit with sufficient input and output channels. We have selected PIC16F877A microcontroller to this purpose. The overall block diagram of the system is given in Fig. 3.

Design and simulation of the electrical circuit is done using PROTEUS software package. Next, The both PI and Fuzzy controllers are designed and simulated using MATLAB. At the following sections, more detail on the structure of the proposed windcatcher, control system, electronic circuits and instrumentation equipment are discussed.

\subsection{Structure}

This system composed of five different parts, namely: 1 . The entrance part which guides the wind into the building, 2. An electric DC motor which provides the required force to track the changes in wind direction, 3. Weather station consists of wind speed sensor and wind direction sensor, 4. Control unit and 5. Power unit which consists of a sealed lead-acid battery and a solarcell panel.

The moving part of the windcatcher is connected to its non-moving part with a flange style coupling which has a ball bearing mechanism between these two parts. So the moving part can rotate freely around its axis. In order to prevent the ball bearing mechanism from dust and to preserve the lubrication, two flexible covers are used on both inner and outer section of coupling.

In the center of the channel there is a shaft connected to both moving and non-moving parts and provides the structural stability of the system.

The rotation force of the windcatcher comes from the teeth of the DC motor which are coupled to the teeth of movable part's flange. The DC motor is not active all the time and it only activates in predefined periods to adjust the direction of the windcatcher. In order to increase the performance of the system some strategies can be added. First of all a humidifier should be considered in the channel. This humidifier can be a wet basement channel or an artificial humidifier. Moreover by using output ways for air, the efficiency of the system will increase through better circulation of the air. Also the output ways can act as a suction system by mounting a dome with a hole on its uppermost curve. This structure is originated from Persian architecture. The air circulation in some places such as bazaar, traditional bathrooms, reservoir and so on are maintained by such a mechanism.

\subsection{Instrumentation}

In this design there are 6 sensors which prepare the essential information for the windcatcher controller. These information are direction of windcatcher, wind direction, wind speed, outdoor temperature, battery voltage and a limit switch respectively. 
The measurement of the windcatcher direction is done by an optical encoder coupled to the DC motor's gearbox. Similarly, another encoder is installed to detect the wind direction. Near the wind direction sensor a tachometer coupled to a propeller measures wind speed. A cheap IC thermometer prepares the outdoor temperatures information. This sensor should be installed in a way that it is protected from direct sunlight. The limit switch provides the reference direction to the controller when it is turned on. The sensory part of this design especially for wind speed/direction and ambient temperature can be simplified by using a weather station package which can be purchased from markets. There are different types of weather stations with wide range of prices but for this application just a simple one that provides the mentioned data is sufficient. Those who give data by a standard serial port like RS232 are preferred.

\subsection{Electronic and Control Design}

To control the direction of windcatcher system, first of all we should define an angle which indicates the position of this windcatcher.

The reference angle is in fact the determinative factor in position of windcatcher. The high efficiency is achievable when the windcatcher stands in correct direction. But the challenge is that how to determine this direction. Before getting in deterministic description of problem, let me clarify the subject conceptually. In hot weather, when the wind is blowing slightly, the intake of windcatcher should be oriented directly into the wind so that a proportion of the wind finds its way into the mounted channels and by passing through wet basement channel cooled and finally passes inside the house and prepares fresh air conditioning. As the wind speeds up, the windcatcher should changes its direction according to the winds orientation to control the amount of air coming indoor until that the normal wind changes into storm. At that case the controller changes the windcatcher's intake direction and positions it opposite to the wind direction so the wind passes the windcatcher and don't enter it.

By a quick brainstorming about the windcatcher, it's obvious that the windcatchers are necessary when it's warm. In cold days or nights the windcatcher should be out of operating and this is achievable by means of an intelligent controller.

The Fuzzy controller plays the rule of a supervisory controller and it is admittedly the intelligent part of the design. The classic PI controller is used to prepare the required control action to do the precise tracking of the Reference direction generated by the Fuzzy controller. Its Proportional and Integral parameters should be tuned according to selected motor's specifications and dynamic of the windcatcher's structure however in this application the performance of the tracking is not emphasized and we just require the tracking controller to do tracking smoothly and precisely for predefined time lapses. So adjusting these parameters to lower levels is more favourable. Further information on designing the Fuzzy controller is given in the next section.

We select PIC16F877A microcontroller from Microchip Inc. to implement the required block diagram. PIC16F877A is a low-cost, highperformance RISC core microcontroller which contains a hardware PWM module, a Watchdog timer and 8 channels ADC [2]. As we need just 5 analogue input channels so without use of any other additional part, the selected microcontroller can perform the required conversion.

\subsection{Software}

Microcontrollers do the required tasks according to the program written and loaded in their ROMs. In our design we do not want that the system become active all the time because we should use the stored energy precisely and do not waste it. So we decide to do the sampling just in every 10 second and require the system to hibernate between sampling. The collected samples are averaged every 10 minutes and after that the PI controller and PWM driver are activated and electric motor starts to turn the windcatcher to track the changes. By using this technique, effects of the turbulent flow of the wind are minimized and the windcatcher just tracks the overall trend of the wind's direction with a little energy consumption.

The PI controller and PWM driver remain active for about 4 time response of the system to ensures the certain tracking and then they are inactivated and they should wait to the next activation period. 


\section{FUZZY CONTROLLER}

The structure built up here is a two-input singleoutput controller. The inputs are the speed of the wind $W_{s}$ and the temperature temp. Consequently, the input to the servo mechanism of windcatcher would be the reference angle, which is actually the summation of the wind's angle with the output of the fuzzy controller. The operational structure of the proposed fuzzy controller is shown in Fig. 4. It consists of three building blocks, namely: 1) a fuzzification block that expresses quantitative action to qualitative action; 2) a fuzzy inference engine that generates the fuzzy rules; and 3) a defuzzification block that articulates qualitative action to quantitative action. Fuzzification translates a numeric value for the speed of wind or temperature into a linguistic value such as high or low with a membership grade [4]. Defuzzification takes the fuzzy output of the rules and generates a "crisp" numeric value used as the control input to the windcatcher.

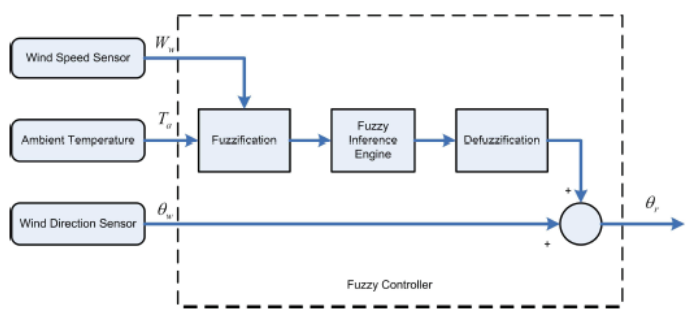

Figure 4 Block Diagram of Fuzzy Controller

The output of fuzzy controller indicates the necessary angular distance between windcatcher's position and wind's direction. In order to get the correct position of windcatcher, the output of fuzzy controller is added to wind's angle. The result is the reference angle which is fed into another linear PI controller to be tracked. The overall system is shown in Fig. 3.

\subsection{Fuzzy Membership and Rule Generation}

The chief problem of the construction of the fuzzy controller is related to the choice of the regulator parameters. Certainly, there is no systematic procedure for the design of a fuzzy controller (membership functions and rules generation), and this section is devoted to the determination of the fuzzy sets and the linguistic rules. In order to define the number of fuzzy set's for wind speed, first of all we should consider the different kind of winds according to their forces.

1. Forces 0 to 2: The wind's speed is up to 11 kilometres per hour and has slight move.

2. Forces 3 to 4 : The wind moves with the speed of 12 to 29 kilometres per hour. There is a breeze which moves flags and wags the leaves of trees.

3. Forces 5 to 6 : With this force the wind's speed goes up from 30 to 50 kilometres per hour.

4. Forces 7 to 9: There is a windstorm with the speed of 51 to 87 kilometres per hour.

5. Forces 10 to 12: The real storm happens with the speed of 88 to 118 kilometres per hour which cause widespread wrecks and destruction.

By using this knowledge about wind, the fuzzy sets for wind speed are defined as follows:

- $\mathbf{N}$ ( Normal): up to $20 \mathrm{~km} / \mathrm{h}$

- SL (Slight): from 20 to $50 \mathrm{~km} / \mathrm{h}$

- ST (Strong): from 51 to $88 \mathrm{~km} / \mathrm{h}$

- STO (Storm): upper than $88 \mathrm{~km} / \mathrm{h}$

The number of the linguistic sets of the temperature is defined by three simple state, namely: hot $H$, moderate $M$, and cold $C$. Additionally, four linguistic sets, i.e. $D, 30 D, 60 D$, and $I D$, have been chosen for the output variable of the fuzzy controller structure.

The scaled input and output membership function sets are shown in Fig. 5 and 6. To obtain the control decision, the Mamdani's inference method is used [3]. It is based on the minimum function to describe the AND operator present in each control rule and the maximum function to describe the $\mathbf{O R}$ operator. The output of the fuzzy controller structure is crisp, and thus, a combined output fuzzy set must be defuzzified. To express the qualitative action in a quantitative action, the sumproduct composition method was used. It calculates the crisp output as the weighted average of the centroids of all output membership functions. 

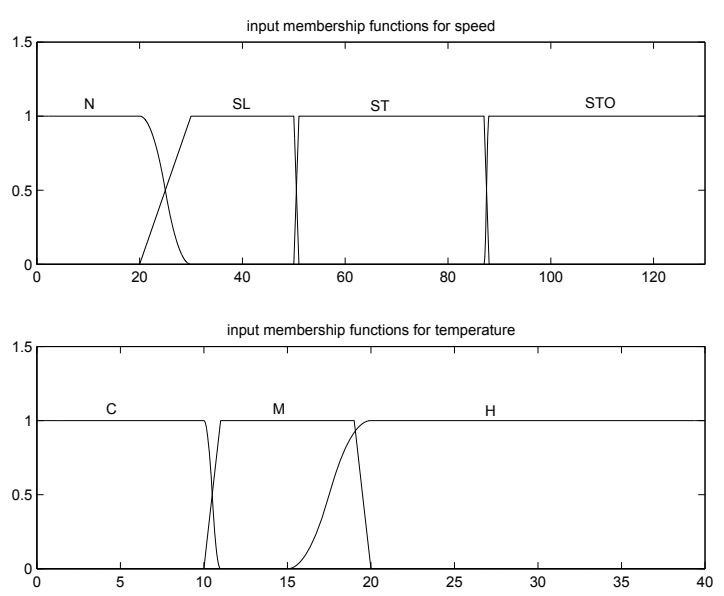

Figure 5 Input Membership Functions

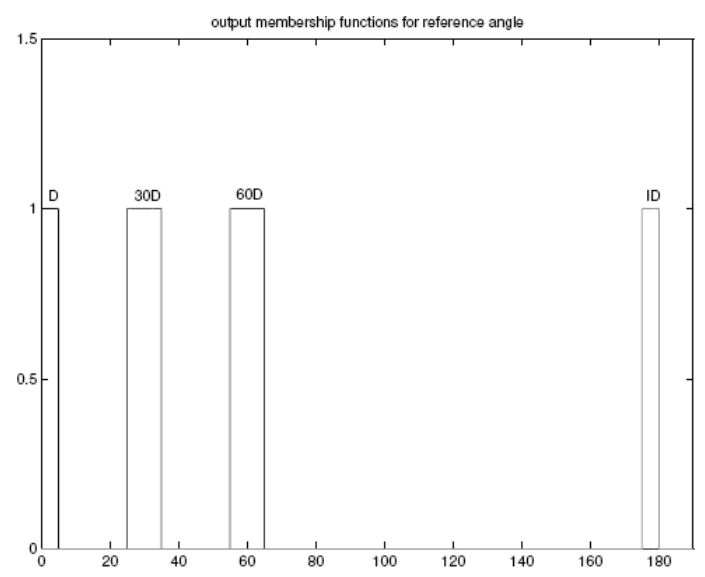

Figure 6 Output Membership Functions

The output of the controller can be expressed as

$$
O_{o}=\frac{\sum_{m}\left(O_{m} \cdot a_{C m} \cdot b_{C m}\right)}{\sum_{m}\left(O_{m} \cdot b_{C m}\right)}
$$

Where $a_{C m}$ and $b_{C m}$ are the centers and widths of the output fuzzy sets, respectively, for $m=1, \ldots, 4$. The values of $b_{C m}$ were chosen to be unity. This scaled output corresponds to the control signal (reference angle) to be applied to maintain the position of windcatcher at a desired angle. Fig. 7 represents the normalized output $O_{o}$ of the proposed fuzzy controller structure as a function of the speed of wind and the temperature. Clearly, it illustrates the nonlinear characteristics of the proposed fuzzy controller structure.

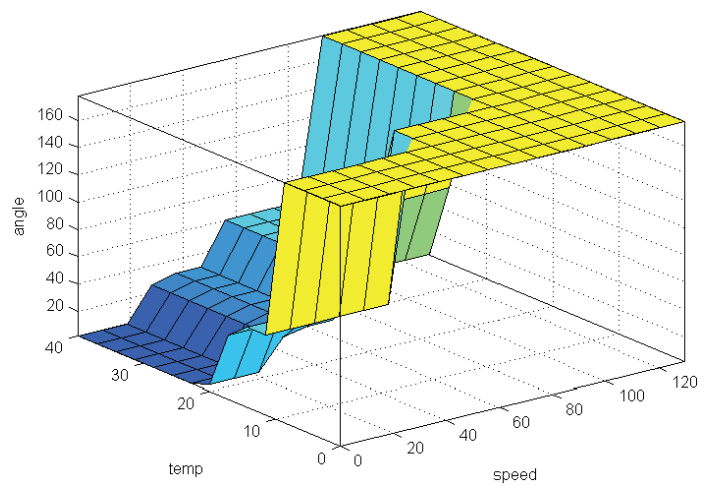

Figure 7 Fuzzy Control Surface

\section{SIMULATION}

To ensure that this windcatcher can be effective in any condition we had test it through 12 different conditions according to three state of temperature(hot, moderate and cold) and four state of wind's speed (Normal, slight, strong and stormy).Test conditions was simulated in MATLAB. Test results illustrates that the proposed fuzzy logic controller structure can provide considerable control performance over a wide range of operating conditions. PI controller's performance was also simulated for a test reference signal using MATLAB. The results are shown in Fig. 8.
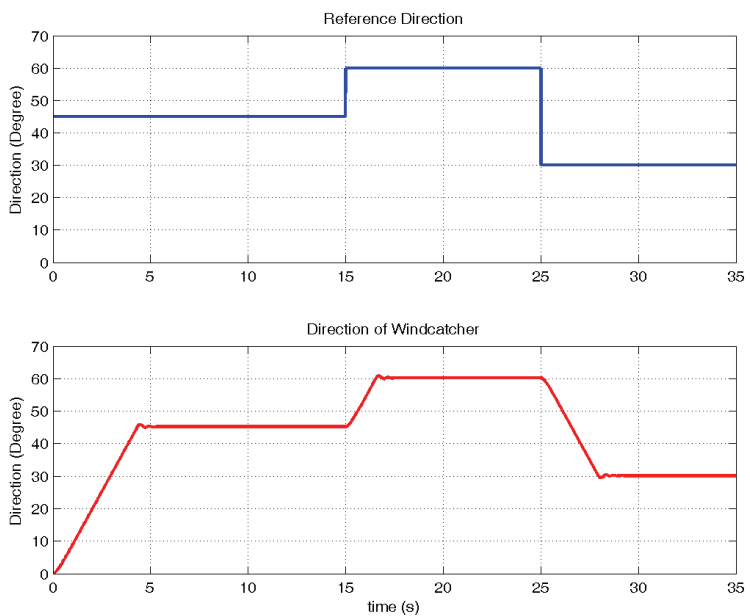

Figure 8 Simulation Results of the Controller 


\section{CONCLUSION}

The main highlights of the proposed design are as follow: at first, Simplicity of the design especially in construction of the mechanical parts. Secondly, not need to costly energy sources alongside with acceptable performance, and thirdly, its low total cost which make it possible to be installed in not developed area. In addition, this system can be installed in remote areas where are far from cross country electrical lines.

As a supplement system one can use a water spray system in the duct. This makes the entered air more pleasant by making it cool and humid. However in this case, we should use a water supply and additional power supply to run the pumps.

\section{REFERENCES}

[1] Bahadori, M. N. (1978) Passive Cooling Systems in Iranian Architecture, Scientific American February, 144-154.

[2] (2003) PIC16F87XA Data Sheet, Microchip Technology Inc. .

[3] Mamdani, E. H. and Assilian, S. (1975) An experiment in linguistic synthesis with a fuzzy logic controller, International Journal of ManMachine Studies, Vol. 7, No. 1, 1-13.

[4] (2002) Fuzzy Logic Toolbox, User's Guide, MathWorks Inc.. 